\title{
Idiopathic sphenoidal defects detected by 3D computed tomography
}

Figure 1 Axial plain CT showing pneumocephalus (arrowheads) ( $\mathrm{A}$ and $\mathrm{B}$ ) and no bone defect in the posterior wall of the sphenoid sinus (arrows) (C-F)
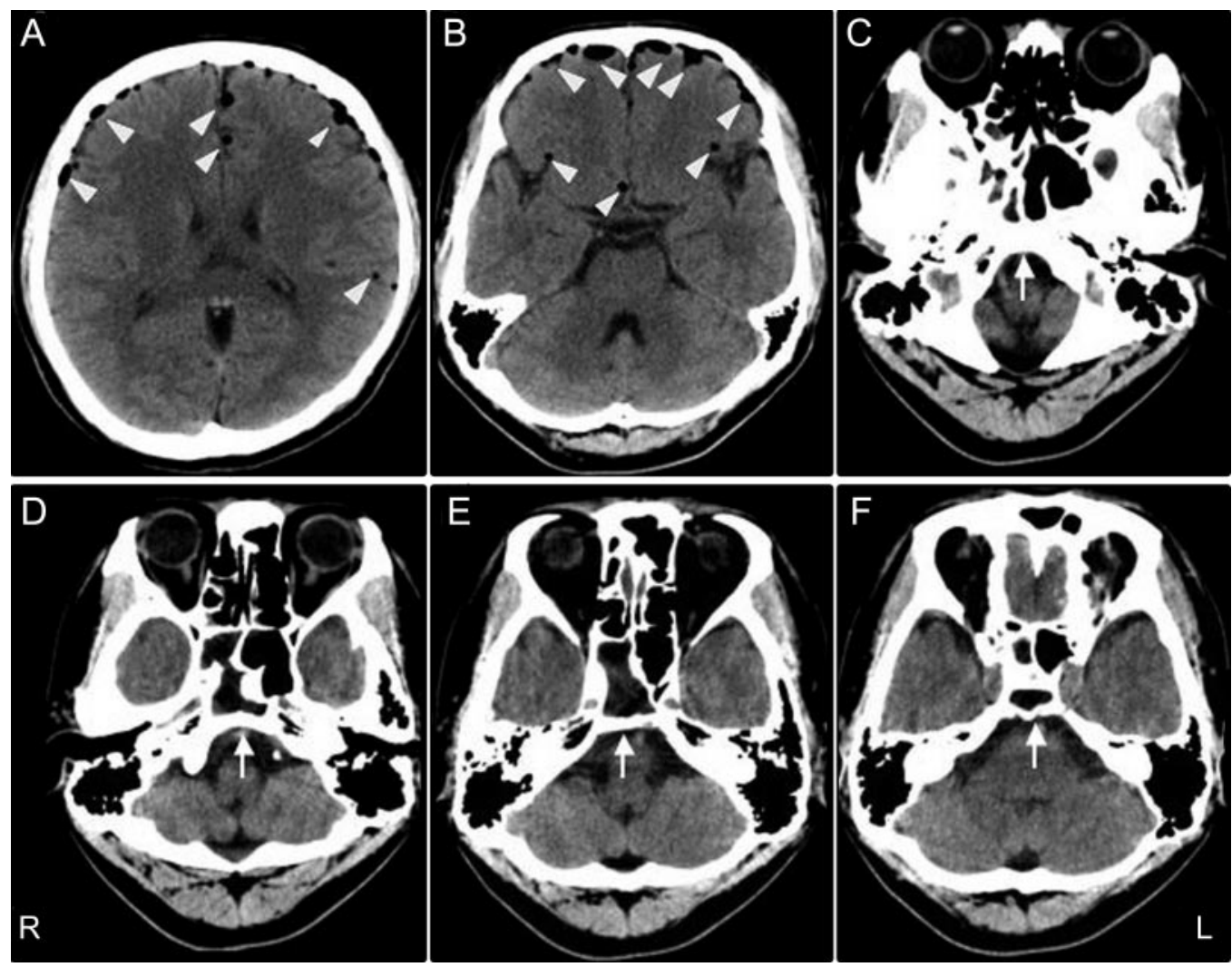

A 38-year-old man with pneumococcal meningitis, pneumocephalus, and CSF rhinorrhea was admitted to our hospital. The CSF rhinorrhea had no traumatic or iatrogenic etiology. The patient was treated with meropenem and recovered from meningitis.

Axial plain CT showed pneumocephalus (figure 1, A and B), but no skull defects. Three-dimensional CT revealed defects of the posterior walls of the sphenoidal sinus (clivus) (figure 2A), which were not seen on plain CT (figure 1, C-F), although it was reported that clivus defects could be detected by axial plain CT.1,2 The defects were repaired with transsphenoidal surgery (figure 2B, see page 158).

Ayumi Hamaguchi, MD, Ryoichi Takahashi, MD, Kazuo Iwasa, MD, PhD, Masahito Yamada, MD, PhD, Kanazawa, Japan

Disclosure: The authors report no disclosures.

Address correspondence and reprint requests to Dr. A. Hamaguchi, Department of Neurology and Neurobiology of Aging, Kanazawa University Graduate School of Medical Science, 13-1, Takara-machi, Kanazawa, Ishikawa, 920-8640, Japan; ashibata@med.kanazawa-u.ac.jp

1. Wakefield BT, Brophy BP. Spontaneous pneumocephalus. J Clin Neurosci 1999;6:174-175.

2. Ahmad FU, Sharma BS, Garg A, Chandra PS. Primary spontaneous CSF rhinorrhea through the clivus: possible etiopathology. J Clin Neurosci 2008;15:1304-1308. 
Figure 2 Three-dimensional CT and transsphenoidal surgery view of the clivus

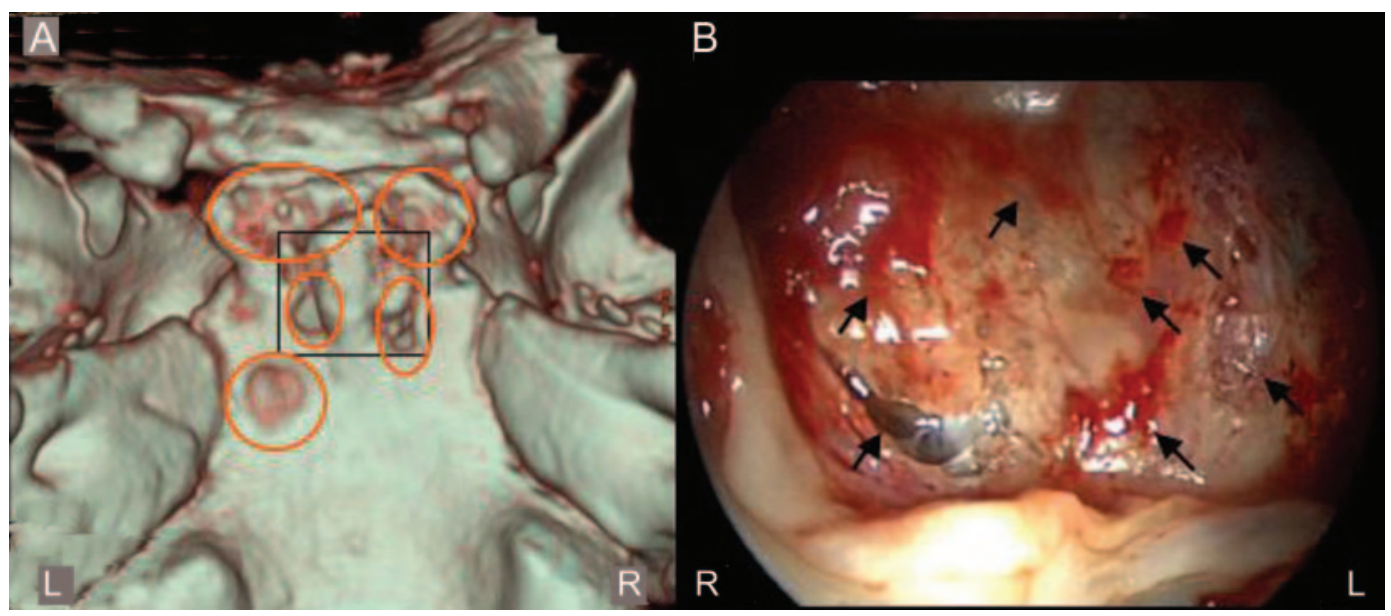

Multiple defects in the clivus were demonstrated by 3-dimensional CT (orange circles) (A). In transsphenoidal surgery, a view from sphenoid sinus, almost corresponding to the opposite side of the black square of $A$, showed some perforations (black arrows) in the thin wall (B). 


\section{Neurology}

\section{Idiopathic sphenoidal defects detected by 3D computed tomography \\ Ayumi Hamaguchi, Ryoichi Takahashi, Kazuo Iwasa, et al. \\ Neurology 2009;73;157-158 \\ DOI 10.1212/WNL.0b013e3181ad53d4}

This information is current as of July 13, 2009

\section{Updated Information \&} Services

References

Permissions \& Licensing

Reprints including high resolution figures, can be found at: http://n.neurology.org/content/73/2/157.full

This article cites 2 articles, 0 of which you can access for free at: http://n.neurology.org/content/73/2/157.full\#ref-list-1

Information about reproducing this article in parts (figures,tables) or in its entirety can be found online at:

http://www.neurology.org/about/about_the_journal\#permissions

Information about ordering reprints can be found online: http://n.neurology.org/subscribers/advertise

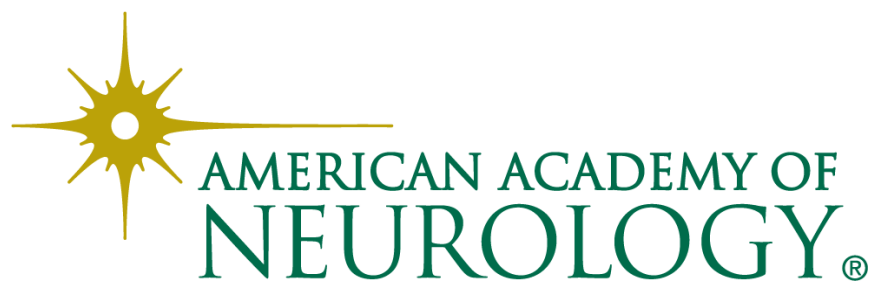

